\title{
Traumatic neuroma of mental nerve following lower lip mucocele excision
}

\author{
Jelena Stepić', Marko Pejović', Miroslav Dragović', Branko Dožić2, Radojica Dražić', Snježana \\ Čolić ${ }^{1}$ \\ 'University of Belgrade, School of Dental Medicine, Department of Oral Surgery, Belgrade, Serbia; \\ ${ }^{2}$ University of Belgrade, School of Dental Medicine, Department of Pathology, Belgrade, Serbia
}

\begin{abstract}
SUMMARY
Traumatic neuroma represents reactive hyperplasia of irregularly positioned Schwann neurofibril cells and connective tissue - stroma that develop as a result of unsuccessful attempts to regenerate peripheral nerve after injury.

This paper presents the case of a patient with painless traumatic neuroma of the lower lip formed in the same place where he previously had surgically removed salivary cyst of minor salivary gland - mucocele. Histopathological examination confirmed the diagnosis of traumatic neuroma.
\end{abstract}

Keywords: traumatic neuroma; lower lip; mucocele

\section{INTRODUCTION}

Nerve severance or damage can inevitably occur during minor oral surgery interventions. That can result in temporary or permanent sensory changes related to the region of nerve distribution. Furthermore, the development of a traumatic neuroma at the injury site can occur as a consequence of nerve damage.

Traumatic neuroma is reactive nonneoplastic process rather than true neoplasm. It's pseudo-tumorous lesion that forms when proximal segment of peripheral nerve undergoes proliferative response while distal segment undergoes Walerian degeneration [1].

Traumatic neuromas, or amputation neuromas, represent a reactive hyperplasia of irregularly arranged Schwann cells and neurofibrils in a connective tissue stroma resulting from unsuccessful attempts of regeneration [2]. These lesions are generally not considered to be frequent but the most common intraoral sites are mental area, lower lip and tongue [3]. However, only few cases of traumatic neuroma have been described on the lower lip $[4,5]$.

The current case report presents traumatic neuroma of mental nerve on the lower lip after mucocele excision was done.

\section{CASE REPORT}

A 41-year old male was referred to the Clinic of Oral Surgery, Faculty of Dentistry, University of Belgrade, Serbia, for extraction of the right maxillary third molar. During clinical examination, the presence of localized submucosal swelling in his lower right fornix was noticed. The patient reported that he had surgical excision of a painless, soft tissue mass of approximately $10 \mathrm{~mm}$ in diameter, localized in his right lower fornix 26 years ago. The histopathological finding has confirmed the clinical diagnosis of mucocele. Postoperatively, the patient experienced numbness on the right side of the lower lip and chin. His symptoms lasted about twelve months and spontaneously disappeared. About thirteen years following the surgery, the patient noticed a soft tissue mass localized in the same place as previous lesion. New lesion has been growing slowly without numbness or any other symptoms therefore the patient did not visit an oral surgeon until the third molar extraction was indicated. Intraoral examination showed a half spherical, movable, firm, painless, soft tissue mass covered by a normal mucosa, measuring 10 $\mathrm{mm}$ in diameter, located in the right lower fornix.

The patient underwent surgical excision of the lesion. During surgical procedure the lesion was easily separated from surrounding tissues. It was connected to mental nerve with a pedicle of $10 \mathrm{~mm}$ in length and $1 \mathrm{~mm}$ in diameter (Figure 1). The pedicle was carefully separated from mental nerve and surgically removed together with the lesion. Both, spherical soft tissue mass and pedicle were sent for histological examination. The day after the surgery the patient had mild burning sensations in the area of the mental foramen. He also complained of a mild skin paresthesia of the chin but not the lip. The third postoperative day all symptoms disappeared.

Microscopically, the lesion was composed of irregularly arranged and interlacing nerve fibres in a fibrous stroma. The lesion comprised spindle cells with scant cytoplasm, elongated oval nuclei arranged in interlacing bundles, and variably sized fascicles with abundant fibrous stroma. Occasionally, a single axon surrounded by Schwann cells was observed in the peripheral areas of the mass (Figure 2). 


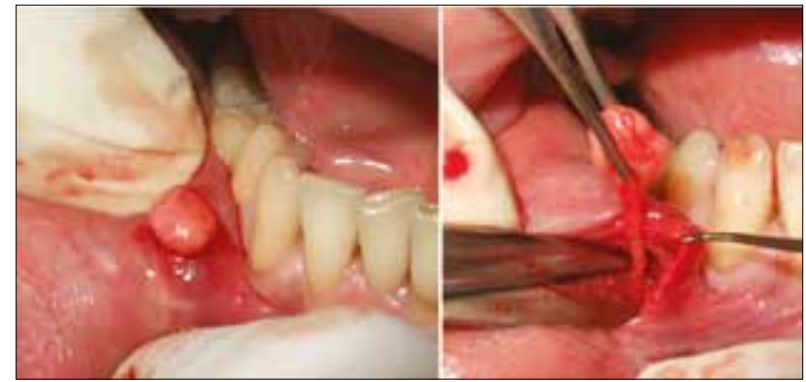

Figure 1. Intraoperative view showing lesion connected to the mental nerve

Slika 1. Intraoperativni nalaz nakon odvajanja od okolnog tkiva. Neurom je peteljkom bio vezan za $n$. mentalis

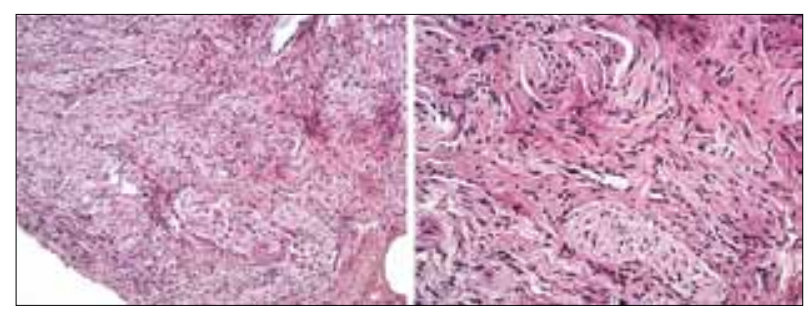

Figure 2. Irregularly arranged and interlacing nerve fibers in a fibrous stroma, HE; $40 \times, 100 \times$

Slika 2. Iregularno raspoređeni i isprepletani snopovi proliferisanih nervnih vlakana u fibroznoj stromi, HE; 40x, 100x

\section{DISCUSSION}

Traumatic neuroma is not a true neoplasm but a reactive proliferation of neural tissue after interruption or other damage of a nerve bundle [6] representing an ineffective attempt of nerve repair [7]. The nerve elements can be injured by different factors, including pressure, ischemia, crushing, cuts, and lacerations, stretching or bleeding into the surrounding area [8].

The most common intraoral sites are mental area, lower lip, and tongue [3]. From surgical trauma point of view, neuromas of mental nerve have been reported to occur following sagittal split osteotomy, chin augmentation, and tooth extraction $[3,7,9-12]$. Clinical findings may vary. The most common symptoms include pain, tenderness and paresthesia $[8,11,13,14]$. The pressure on a local area may aggravate the pain. Infiltration of local anesthesia into the painful region provides relief [11, $13,14]$. However, $25 \%$ cases of traumatic neuromas could be asymptomatic lesions which confuses diagnosis [15].

In our paper the case of painless traumatic neuroma is presented. Considering that painless lesion occurred at the same site as previous lesion we firstly assumed that it was newly formed mucocele. We came to that conclusion as mucocele is one of the most common oral lesions on the lower lip according to numerous authors [16]. Mucocele is developed after an injury of a minor salivary duct, usually after biting trauma and a spillage of mucus into the surrounding submucosal connective tissue as a consequence. The most common complaint is painless swelling. Depending on location the clinical appearance is different. The superficial lesions are blue and fluctuant while deeper ones have normal color of mucosa and they are firm. The clinical findings in our patient corresponded to the clinical presentation of deeper mucocele lesions. The treatment of choice was surgical excision of the mucocele and surrounding minor salivary glands. But, improper surgical treatment as well as continued lip biting habits could result in recurrence as described in $27.78 \%$ of cases [17]. However, as the new lesion appeared thirteen years later it was less likely to be mucocele recurrence. On the other hand there was a great possibility that new mucocele or some other benign connective tissue lesion have been developed. Beside mucocele the differential diagnosis included fibrolipoma, schwannoma, neurofibroma, fibroephithelial polyp and small salivary gland tumors.

Traumatic neuroma can be differentiated from fibrolipoma by the lack of lobular pattern, fibrosis and absence of lipoblasts [18]. Traumatic neuroma differs from schwanoma by a more superficial position, absence of Antoni type tissues architecture, and additional number of axons and myelin sheaths within the lesion. Neurofibromas have expansive growth, usually are located deeply, and have no specific site of occurrence. They exhibit pattern in which cells are arranged in short fascicles. They are commonly found in patients with Von Recklinghausen's disease that was not present in our case. Traumatic neuroma differs from neurofibroma in the presence of broader fascicles with more axons and myelin sheath and also the lack of significant mucopolysaccaride ground substance and mast cells [18].

Mucocele is one of the most common lesions of lower lip and preliminary diagnosis was based on that fact. During the surgical treatment it was found that the lesion was connected to mental nerve suggesting neural origin of the lesion. Also the spherical mass neither matched in color nor in consistency with deep mucocele. The histological features of the mass were consistent with the diagnosis of traumatic neuroma. Treatment of choice for traumatic neuroma is surgical excision. Apart classical surgical excision another techniques like cryosurgery and laser therapy could be a method of choice for the treatment of traumatic neuroma.

In this case we assumed that traumatic neuroma had occurred as a result of tissue damage by blade during the previous surgical excision of mucocele or by needle during local anaesthetic administration. This is supported by the fact that after the first surgical intervention patient complained about lower lip paraesthesia that lasted about a year.

In conclusion, nerve injury and consequently traumatic neuroma are possible by-effects of mucocele excision even though it is not a major facial surgical procedure.

\section{REFERENCES}

1. Barnes L. Surgical Pathology of the Head and Neck. 2. ed: Taylor \& Francis; 2000

2. Zachariades N, Mezetis M, Vairaktaris E, Triantafyllou D, Skoura-Kafoussia C, Konsolaki-Agouridaki E, et al. Benign neurogenic tumors of the oral cavity. Int J Oral Maxillofac Surg. 1987; 16(1):70-6. [PMID: 3031179]

3. Sist TC Jr, Greene GW. Traumatic neuroma of the oral cavity. Report of thirty one new cases and review of the literature. Oral Surg Oral Med Oral Pathol. 1981; 51(4):394-402. [PMID: 6940077] 
4. Tashiro A. Imafuku S, Furue M. Traumatic neuroma of the lower lip with intraepithelial nerve fibers. J Cutan Pathol. 2008; 35(3):320-3. [DOI: 10.1111/j.1600-0560.2007.00801.x] [PMID: 18251748]

5. Zhang $M$, Hayashi $H$, Fukuyama $H$, Nakamura T, Kurokawa $H$, Takahashu T. Traumatic neuroma in the lower lip arising following laser/cryosurgery to treat a mucocele. Oral Dis. 2003; 9(3):160-1. [DOI: 10.1034/j.1601-0825.2003.02917.x] [PMID: 12945599]

6. Neville WB, Damm DD, Allen CM, Bouquot JE. Oral and Maxillofacial Pathology (2nd ed), Philadelphia, Pennsylvania, W.B. Saunders Company 2002. $454 \mathrm{p}$.

7. Peszkowski MJ, Larsson A. Extraosseous and intraosseous oral traumatic neuromas and their association with tooth extraction. J Oral Maxillofacial Surg. 1990; 48(9):963-7. [DOI: 10.1016/02782391(90)90010-Y] [PMID: 2395049]

8. Swanson $\mathrm{HH}$. Traumatic neuromas: a review of literature. Oral Surg Oral Med Oral Pathol. 1961; 14(3):317-26. [PMID: 13774228]

9. Arribas-Garcia I, Alcala-Galiano A, Gutierrez R, Montalvo-Moreno J). Traumatic neuroma of the inferior alveolar nerve: a case report. Med Oral Patol Oral Cir Bucal. 2008; 13(3):E186-8. [PMID: 18305440]

10. Kallal RH, Ritto FG, Almeida LE, Crofton D), Thomas GP. Traumatic neuroma following sagittal split osteotomy of the mandible. Int J Oral Maxillofac Surg. 2007; 36(5):453-4. [DOI: 10.1016/j.ijom.2006.10.017] [PMID: 17239560]

11. Sayan NB, Ucok C. Asymptomatic traumatic neuroma after mandibular sagittal split osteotomy: a case report. J Oral Maxillofacial
Surg. 2002; 60(1):111-2. [DOI: 10.1053/joms.2002.29088] [PMID: 11757021]

12. Deng W, Chen SL, Huang DY. Traumatic neuroma of mental nerve following chin augmentation. Int J Oral Maxillofac Surg. 2009; 38(12):1324-6. [DOI: 10.1016/j.ijom.2009.06.020] [PMID: 19643576]

13. Chau MN, Jonsson E, Lee KM. Traumatic neuroma following sagittal mandibular osteotomy. Int J Oral Maxillofac Surg. 1989; 18(2):95-8. [DOI: 10.1016/S0901-5027(89)80139-0] [PMID: 2501416]

14. Rasmussen OC. Painful traumatic neuromas in oral cavity. Oral Surg Oral Med Oral Pathol. 1980; 49(3):191-5. [PMID: 6928298]

15. Cawson RA, Binnie WH, Speight PM, Barrett AW, Wright JM. Lucas's Pathology of tumors of the oral tissues ( 5 ed). New York, NY, Churchill Livingstone 1998.

16. Re Cecconi D, Achilli A, Tarozzi M, Lodi G, Demarosi F, Sardella A, et al. Mucoceles of the oral cavity: a large case series (1994-2008) and a literature review. Med Oral Patol Oral Cir Bucal. 2010; 15(4):551-6. [DOI: 10.4317/medoral.15.e551] [PMID: 20038883]

17. Jani DR, Chawda J, Sundaragiri SK, Parmar G. Mucocele - A study of 36 cases. Indian J Dent Res. 2010; 21(3):337-40. [DOI: 10.4103/09709290.70793] [PMID: 20930340]

18. Panthula VR. "Rare or Underdiagnosed?" - Solitary Circumscribed Neuroma of the Lip. J Clin Diagn Res. 2015; 9(7):ZD32-ZD34. [DOI: 10.7860/JCDR/2015/14332.6255] 


\title{
Traumatski neurom mentalnog nerva nakon ekscizije mukokele donje usne
}

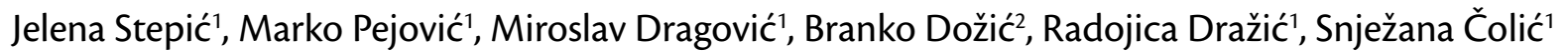 \\ 'Univerzitet u Beogradu, Stomatološki fakultet, Klinika za oralnu hirurgiju, Beograd, Srbija; \\ ${ }^{2}$ Univerzitet u Beogradu, Stomatološki fakultet, Institut za patologiju, Beograd, Srbija
}

\begin{abstract}
KRATAK SADRŽAJ
Traumatski neurom predstavlja reaktivnu hiperplaziju iregularno postavljenih Švanovih ćelija i neurofibrila u vezivno-tkivnoj stromi koja nastaje kao posledica neuspešnih pokušaja regeneracije nakon povrede perifernog nerva.

U ovom radu je prikazan slučaj pacijenta sa bezbolnim traumatskim neuromom donje usne koji se pojavio na istom mestu gde je prethodno hirurški uklonjena salivarna cista male pljuvačne žlezde donje usne - mukokela. Histopatološki nalaz je pokazao da je uklonjena promena bila traumatski neurom.

Ključne reči: traumatski neurom; donja usna; mukokela
\end{abstract}

\section{UVOD}

Opšte je poznato da u toku oralno-hirurških intervencija može doći do povrede nervnih struktura. Kao posledica, dolazi do subjektivnih senzornih ili motornih promena u inervacionoj zoni povređenog nerva. Osim toga, ponekad postoje i objektivni znaci koji se mogu manifestovati pojavom traumatskog neuroma na mestu povrede.

Traumatski neurom predstavlja reaktivnu ne-neoplastičnu leziju više nego pravu neoplazmu. Ovaj patološki entitet je poznat kao pseudotumor i nastaje usled proliferatibnog odgovora proksimalnog segmenta perifernog nervnog vlakna, dok distalni segment podleže Valerovoj degeneraciji (Wallerian degeneration) [1].

Traumatski neurom, odnosno amputacijski neurom, predstavlja reaktivnu hiperplaziju iregularno postavljenih Švanovih ćelija i neurofibrila u vezivno-tkivnoj stromi koja nastaje kao posledica neuspešnih pokušaja regeneracije [2]. Ove lezije nisu česte, a uobičajena mesta pojave u usnoj duplji su područja bradnog otvora, donje usne i jezika [3]. Kada je u pitanju područje donje usne, u literaturi postoji samo nekoliko opisanih slučajeva traumatskog neuroma $[4,5]$.

$\mathrm{U}$ ovom radu opisan je traumatski neurom bradnog nerva $\mathrm{u}$ području donje usne, nastao nakon ekscizije mukokele.

\section{PRIKAZ PACIJENTA}

Četrdesetjednogodišnji muškarac primljen je na Kliniku za oralnu hirurgiju Stomatološkog fakulteta Univerziteta u Beogradu radi ekstrakcije gornjeg desnog umnjaka. U toku kliničkog pregleda primećeno je prisustvo submukoznog, loptastog, jasno ograničenog otoka u predelu donje usne sa desne strane. Pacijent je naveo da je pre 26 godina bio podvrgnut hirurškoj eksciziji bezbolne mekotkivne strukture prečnika $1 \mathrm{~cm}$ koja je bila lokalizovana na istom mestu. Promena je klinički odgovarala mukokeli, što je potvrđeno histopatološkom analizom. Nakon operacije pacijent se žalio na utrnulost u regiji desne polovine donje usne i brade. Prema rečima pacijenta, simptomi su trajali oko 12 meseci, nakon čega su spontano iščezli. Trinaest godina posle operacije pacijent je primetio novu mekotkivnu promenu na mestu prethodne lezije. Tokom tog perioda lezija se uvećavala veoma sporo (bez utrnulosti, kao i bilo kakvih drugih simptoma), te pacijent nije došao na pregled sve dok ekstrakcija gornjeg trećeg molara nije bila indikovana. Intraoralnim pregledom je ustanovljeno postojanje polukružne, pokretne, čvrste i bezbolne mekotkivne strukture koja je prekrivena normalnom sluzokožom, čija je veličina bila $10 \mathrm{~mm}$ u prečniku. Pacijentu je sugerisano hirurško uklanjanje lezije. U toku operacije lezija je lako odvojena od okolnog tkiva i primećeno je da je peteljkom dužine oko $10 \mathrm{~mm}$ povezana sa mentalnim nervom (Slika 1). U skladu sa tim, peteljka je pažljivo odvojena od mentalnog nerva i uklonjena zajedno sa lezijom. Odstranjeno tkivo zajedno sa peteljkom poslato je na histopatološku analizu. Prvog postoperativnog dana pacijent je prijavio osećaj pečenja u zoni projekcije mentalnog otvora. Takođe, naveo je i blagi osećaj parestezije kože brade, ali ne i usne. Tri dana nakon operacije svi simptomi su nestali.

Mikroskopski, lezija se sastojala od iregularno raspoređenih $\mathrm{i}$ isprepletanih nervnih vlakana u fibroznoj stromi. Pored toga, tkivo je sadržalo i vretenaste ćelije sa oskudnom citoplazmom, izduženim ovalnim jedrom, raspoređene u međusobno isprepletanim snopovima različitih veličina uz obilje fibrozne strome. Mestimično, pojedinačni akson okružen Švanovim ćelijama nalazio se u perifernim delovima tumorskog tkiva (Slika 2).

\section{DISKUSIJA}

Traumatski neurom nije neoplazma u pravom smislu te reči, već reaktivna proliferacija nervnog tkiva koja nastaje nakon prekida ili neke druge povrede nervnog snopa [6] i predstavlja neuspešan pokušaj nervne regeneracije [7]. Nervni elementi mogu biti povređeni delovanjem različitih faktora uključujući pritisak, ishemiju, nagnječenje, presecanje, kao i laceracije, rastezanje i krvarenje u okolnom tkivu [8]. Što se tiče intraoralne lokalizacije, traumatski neurom se najčešće javlja u području bradnog otvora, donje usne i jezika [3]. Sa aspekta hirurške traume, pojave neuroma mentalnog nerva su opisane nakon sagitalne osteotomije, koštane augmentacije bradnog predela, ali i vađenja zuba [3, 7, 9-12].

Klinički simptomi mogu varirati. Uobičajena klinička slika uključuje bol, žarenje i paresteziju $[8,11,13,14]$. Bol se može pojačati pritiskom na zahvaćenu regiju. Infiltracija lokalnog anestetičkog rastvora u bolno područje donosi olakšanje [11, $13,14]$. Sa druge strane, u 25\% pacijenata traumatski neuromi 
mogu biti asimptomatske lezije, što često otežava postavljanje dijagnoze [15].

U ovom radu je prikazan slučaj bezbolnog traumatskog neuroma. Budući da se bezbolna mekotkivna formacija javila na istom mestu kao i prethodna lezija, postojala je pretpostavka da se radi o recidivu mukokele. Mukokele su jedan od najčešćih patoloških entiteta usne duplje i predominantno se javljaju u regiji donje usne [16]. Nastaju kao posledica povrede malih pljuvačnih kanala i žlezda, najčešće ugrizanjem. Usled oštećenja salivarnog kanala dolazi do izlivanja mukusa u okolno submukozno vezivno tkivo. Najčešći simptom na koji se pacijenti žale je bezbolni otok. Treba istaći da klinička slika zavisi od lokalizacije. Površno lokalizovane lezije su plavičaste boje i pokazuju fenomen fluktuacije, dok su dublje lezije tvrđe i imaju boju normalne sluzokože. Terapija ovih lezija je hirurška i podrazumeva eksciziju mukokele i uklanjanje okolnih malih pljuvačnih žlezda. Neadekvatna hirurška tehnika kao i dalje prisustvo navike grickanja usne mogu rezultovati recidivom $\mathrm{u}$ $27,78 \%$ pacijenata [17].

Klinički nalaz kod pacijenta iz ovog rada je odgovarao kliničkoj slici dublje lokalizovane mukokele. Kako je do pojave nove lezije došlo 13 godina nakon prve intervencije, manje je verovatno da je u pitanju recidiv. Sa druge strane, postojala je velika mogućnost da je u pitanju nova mukokela ili neka druga benigna mekotkivna struktura.

Diferencijalno dijagnostički, pored mukokele, u vidu treba imati fibrolipom, švanom, neurofibrom, fibroepitelijalni polip i tumor malih pljuvačnih žlezda. Traumatski neurom se može razlikovati od fibrolipoma po odsustvu lubalarne građe, fibroze kao i masnih ćelija [18]. Sa druge strane, od švanoma se razlikuje po tome što je obično postavljen površnije. Takođe, odusustvo Antoni tipa tkivne arhitekture i veći broj aksona i mijelinskih struktura ukazuju na to da je u pitanju traumatski neurom pre nego švanom. Neurofibromi imaju ekspanzivan rast, obično su lokalizovani dublje u tkivu i nemaju specifično mesto nastajanja. Odlikuje ih građa u kojoj su ćelije raspoređene u kratkim snopovima. Po pravilu se javljaju kod pacijenata sa von Recklinghausenovom bolešću, što nije bio slučaj kod prikazanog pacijenta u ovom radu. Traumatski neurom se od neurofibroma razlikuje po prisustvu širih snopova sa više aksona i mijelinskih obloga, kao i po odsustvu značajne količine mukopolisaharida i mast ćelija [18].

Mukokela je jedna od najčešćih lezija donje usne, te je tako i privremena dijagnoza postavljena u ovom slučaju. $U$ toku operacije ustanovljeno je da je lezija povezana sa mentalnim nervom, što je ukazalo na to da lezija može biti porekla nervnog tkiva. Pored toga, ni boja ni konzistencija lezije nisu odgovarale mukokeli.

Ono što je važno istaći je to da hirurška ekscizija predstavlja tretman izbora za traumatski neurom. Osim klasične hirurške ekscizije postoje i druge tehnike lečenja kao što su kriohirurgija i terapija laserom. Zahvaljujući manjoj invazivnosti, ove tehnike se nameću kao dostojna alternativa klasičnoj hirurgiji.

Histopatološka analiza je nesumnjivo potvrdila da je u pitanju traumatski neurom. Na osnovu preoperativnih anamnestičkih podataka i podataka dobijenih nakon operacije, kao i histopatološkog nalaza, traumatski neurom je najverovatnije nastao kao posledica povrede skalpelom tokom prethodne hirurške intervencije, ili povrede iglom u toku aplikacije lokalnog anestetičkog rastvora ili šivenja.Takođe, ovo potkrepljuje i podatak da se nakon prve operacije pacijent žalio na paresteziju donje usne.

Može se zaključiti da je povreda nerva i posledična pojava traumatskog neuroma jedna od mogućih komplikacija ekscizije mukokele, iako ova intervencija ne predstavlja ekstenzivnu oralnohiruršku proceduru. Imajući u vidu da je usna izgrađena od vezivnog i masnog tkiva, krvnih sudova, nerava i pljuvačnih žlezda, jasno je da svaki tumor usne može imati širok spektar diferencijalno dijagnostičkih patoloških entiteta. Kako je klinička prezentacija benignih i malignih tumora u regiji usne veoma slična, eksciziona biopsija je neophodna kako bi se mogla postaviti sigurna dijagnoza. 